\title{
Reference Region
}

National Cancer Institute

\section{Source}

National Cancer Institute. Reference Region. NCI Thesaurus. Code C94970.

A region of interest in an image chosen for comparison purposes because its uptake properties have some desired feature. 